\title{
Orthodontic retention and the role of the general dental practitioner
}

\author{
Charlotte Molyneaux, ${ }^{1}$ Jonathan R. Sandy ${ }^{1}$ and Anthony J. Ireland*1
}

\section{Key points}

Outlines why long-term orthodontic retention is needed for stability of tooth positions after orthodontic treatment.
Highlights the importance of the general dental practitioner's role in long-term orthodontic retention and the need for good communication between orthodontists and general dental practitioners.
Suggests how communication between orthodontists and general dental practitioners might be improved.

\begin{abstract}
Introduction Long-term orthodontic retention using removable or fixed retainers is needed to maintain the outcome of orthodontic treatment. The aim of this article is to describe how long-term retention is managed and to report on a survey of general dental practitioners (GDPs) as to how this management currently operates in the UK.

Materials and methods GDPs were invited to complete a short online survey on orthodontic retention using an open notice posted in the British Dental Journal and a direct email to the members of a local dental clinical society.

Results Fifty-six GDPs completed the online survey. Overall, the findings highlighted poor levels of communication between orthodontists and GDPs with respect to the latter assuming responsibility for the management of long-term retention.

Conclusion The management of long-term retention could be improved by more effective communication between the orthodontist and GDP. One solution might be a retention management pro forma. GDPs are in some instances willing to undertake more of the management of retention following further training and possible remuneration.
\end{abstract}

\section{Introduction}

Following correction of a malocclusion, there is a risk of change in tooth position, either because unstable tooth movements have been undertaken as part of orthodontic treatment or due to other uncontrollable factors such as facial growth. Continued facial growth is part of the normal ageing process ${ }^{1,2}$ and is known to occur well into middle age. ${ }^{3}$ It is therefore now broadly accepted that most patients require long-term retention to maintain the alignment of the teeth and, by implication, to remain satisfied with their final orthodontic result.

There is disagreement concerning the risks of relapse and the threshold at which it

${ }^{1}$ Child Dental Health, Bristol Dental School, University of Bristol, Lower Maudlin Street, Bristol, BS1 2LY, UK.

*Correspondence to: Anthony J. Ireland

Email address: tony.ireland@bristol.ac.uk

Refereed Paper.

Accepted 2 November 2020

https://doi.org/10.1038/s41415-021-2875-5 becomes of concern. If any degree of relapse is unacceptable, this would place particular onus on prevention. These issues have implications for the management of orthodontic retention in both the short and the long term, and for whoever is managing it, be it the orthodontist or the general dental practitioner (GDP).

While the benefits of retention in maintaining anteroposterior and vertical correction are less clear-cut, with respect to the development of lower anterior malalignment, the number of years without a retainer has been found to be a strong predictor of post-treatment change, ${ }^{4}$ with a reported odds ratio (OR) of 1.32 (95\% CI $1.03-1.68)$. The presence of a bonded retainer is also a strong predictor of stability (OR: 0.31; $95 \%$ CI 0.10-0.98). As such, the need for retention to maintain alignment is apparent, although there has been less research concerning the impact of relapse on patient satisfaction.

The perceptions of change and degrees of acceptability and possible need for re-treatment among lay people have increasingly been sought. Alqahtani et al. $(2012)^{5}$ reviewed lower incisor irregularity and, unsurprisingly, orthodontists were found to have a lower tolerance for lower incisor malalignment than lay persons. Interestingly, within the latter group, the threshold for treatment was lower in those who had previously undergone orthodontic treatment when compared to those who had not. A similar, though less convincing, trend was also seen in a follow-up study focusing on upper incisal irregularity. ${ }^{6}$

Chow et al. $(2020)^{7}$ investigated factors that may have led to relapse in patients who were seeking re-treatment, comparing the original malocclusion to their relapsed state. The factors that were thought to contribute to relapse once again included poor original treatment, maturational changes, unfavourable growth and inadequate retention. The primary driver in seeking re-treatment was aesthetics. Patients who have previously undergone treatment not only appeared to notice malalignment more than untreated lay persons, but may also present for re-treatment with a less severe malocclusion. 
The choice of retainer is often based on the personal preferences and the experience of the treating orthodontist. ${ }^{8}$ Factors that can influence the choice of retainer include the pre-treatment tooth positions such as multiple tooth rotations, a median diastema, the depth of the initial overbite, the degree of interdigitation post-treatment, periodontal status and oral hygiene. ${ }^{9}$ However, the scientific evidence concerning the best type of retainer is equivocal, at least in the short term. ${ }^{10}$

Irrespective of retainer type, it is important that wear is monitored over the long term. It has been suggested that the treating orthodontist should monitor retainer wear for the first two years after placement, particularly in the case of bonded fixed retainers. This is because most bond failures with these types of retainers occur within two years of placement. ${ }^{11}$

Within the publicly funded National Health Service (NHS), there is a requirement for supervision of orthodontic retention by the treating orthodontist for a minimum 12-month period following completion of active treatment. ${ }^{12}$ Although a minimum 12 -month period is the requirement, in all likelihood, it is unlikely to extend beyond this as no further payments are made after this time period. Whether retention is supervised by the orthodontist for 12 or indeed 24 months following active treatment, there will come a point when the patient is most likely going to be discharged by the orthodontist, back to the care of the GDP. This relates to capacity issues, meaning that orthodontists are typically unable to review retention indefinitely. ${ }^{9}$ While the possibility of remote monitoring of orthodontic retention is becoming more established, ${ }^{13,14}$ the expectation may also be for the patient to monitor their own tooth alignment and retainers. This prospect is perhaps somewhat daunting, with a lack of follow-up appointments linked to independent decisions to continue or cease retainer wear. ${ }^{15}$ Alternatively, the orthodontist may expect the GDP to monitor the occlusion and retainers during routine general dental check-ups. However, if the expectation is for annual retainer checks in conjunction with the patient's recommended general dental recalls, it begs a series of questions, including:

- Are GDPs happy to participate in supervising orthodontic retention?

- Are they formally asked to supervise the orthodontic retention of their patients by the orthodontist?
- Does the orthodontist provide guidance in the form of a protocol for retention?

- Should patients bring their removable retainers to be checked by their GDPs?

- Do GDPs enquire about/inspect the retainers of patients at their routine general dental check-ups?

- What would a GDP supervising orthodontic retention be happy to do? For example, would they be comfortable repairing or replacing a fixed or removable retainer?

Indeed, the need for clarity concerning the responsibility of monitoring of long-term retention has been previously suggested, ${ }^{16}$ along with other considerations such as the orthodontic records being made available to the GDP when any transfer of care is made, together with the provision of appropriate training. Similarly, Littlewood $(2017)^{17}$ suggested appropriate remuneration and training for GDPs taking over the responsibility for long-term orthodontic retention. Specifically, training on detection of failing bonded retainers along with their repair and replacement, the ability to monitor the fit of removable retainers, to motivate patients to wear and look after their retainers, to monitor the effect of retainers on oral health and to make any necessary adjustments were advocated. A short online survey of GDPs aiming to explore their perception of roles and responsibilities regarding the monitoring of orthodontic retention was therefore undertaken.

\section{Materials and methods}

This was a cross-sectional study which utilised a short online questionnaire (Appendix 1). Ethical approval to run the questionnaire was granted by the University of Bristol Faculty Ethics Committee (ref: 106204). In order to recruit GDPs to determine their views on orthodontic retention, a notice was published in the 10 July 2020 issue of the British Dental Journal, along with an e-mail sent to the members of the dental section of the Clinical Society of Bath. The questionnaire remained open until 31 August 2020.

The questionnaire was developed and piloted on ten UK-based GDPs for understanding, interpretation and time taken to complete. Feedback resulted in adjustments to the wording and a completion time of less than five minutes. These responses were not included in the final analysis. The survey was administered and results collected using Bristol Online Surveys.

\section{Results}

A total of just 56 responses were received for the questionnaire. Of the GDPs, 72\% held an NHS general dental practice contract and $10 \%$ also an NHS orthodontic contract. The percent responses to each question are illustrated in Table 1.

Taking each question in turn:

- Q1: Do you receive correspondence from the orthodontist requesting that you now monitor the orthodontic retainers at the end of treatment? - Only $7.1 \%$ said 'always' with $44.6 \%$ answering 'never'

- Q2: Does the correspondence give any specific information/ guidance? - None responded 'always' and 62\% 'never'

- Q3: Do you routinely enquire about/ inspect the retainers of your patients at their routine general dental check-ups? - $8.9 \%$ responded 'never' and only $21.4 \%$ responded 'always'

- Q4: If you do enquire/inspect the retainers at their routine check-ups, do you record your findings in their clinical record? - For this question, there were only 51 responses out of the total of 56 respondents. Of these, only $31.4 \%$ stated 'always' and $7.8 \%$ stated 'never'

- Q5: Do your patients tend to bring their removable retainers to you to be reviewed at their routine general dental check-ups? - None said 'always' and $46.4 \%$ said 'hardly ever'.

The next series of questions concerned damaged or lost removable and bonded retainers:

- Q6: What would you do if the patient has fractured their removable retainer? $55.5 \%$ said they would repair the removable retainer with a private charge, $10.7 \%$ with an NHS charge and $25 \%$ would refer the patient to an orthodontist

- Q7: What would you do if the patient has lost their removable retainer? - Once again, a high percentage (57.1\%) would replace the removable retainer with a private charge, $12.5 \%$ with an NHS charge and $21.5 \%$ would refer the patient to an orthodontist

- Q8: What would you do if a bonded retainer has just detached from one or more teeth, but the retainer is intact, the teeth remain well aligned and the retainer could be repaired? - Here, $35.7 \%$ said they would repair the bonded retainer with a private charge, 32.2\% with an NHS charge and 25\% would refer the patient to an orthodontist 
Table 1 Percent scores for each of the answers within the online questionnaire. There were a total of 56 responses in each case (except for the question highlighted with an asterisk on recording outcomes within the clinical record where there were only 51 responses)

Answer within the questionnaire

\begin{tabular}{|c|c|c|c|c|c|c|}
\hline \multicolumn{2}{|l|}{ Question } & Always & $\begin{array}{l}\text { Most of the } \\
\text { time }\end{array}$ & Sometimes & Hardly ever & Never \\
\hline \multicolumn{2}{|c|}{$\begin{array}{l}\text { Do you receive correspondence from the orthodontist requesting that you now } \\
\text { monitor the orthodontic retainers at the end of treatment? }\end{array}$} & 7.1 & 8.9 & 23.2 & 16.1 & 44.6 \\
\hline \multicolumn{2}{|c|}{$\begin{array}{l}\text { Does the correspondence give any specific information/guidance such as 'please } \\
\text { monitor retainers annually' or 'please refer back if there are any problems'? }\end{array}$} & 0 & 8.9 & 19.7 & 10.7 & 62 \\
\hline \multicolumn{2}{|c|}{$\begin{array}{l}\text { Do you routinely enquire about/inspect the retainers of your patients at their } \\
\text { routine general dental check-ups? }\end{array}$} & 21.4 & 25 & 32.2 & 12.5 & 8.9 \\
\hline \multicolumn{2}{|c|}{$\begin{array}{l}\text { If you do enquire/inspect the retainers at their routine check-ups, do you record } \\
\text { your findings in their clinical record?*}\end{array}$} & 31.4 & 21.6 & 19.6 & 19.6 & 7.8 \\
\hline \multicolumn{2}{|c|}{$\begin{array}{l}\text { Do your patients tend to bring their removable retainers to you to be reviewed at } \\
\text { their routine general dental check-ups? }\end{array}$} & 0 & 5.5 & 23.1 & 46.4 & 25 \\
\hline \multicolumn{3}{|l|}{ Question } & $\begin{array}{l}\text { Repair/ } \\
\text { replace with } \\
\text { NHS charge }\end{array}$ & $\begin{array}{l}\text { Repair/ } \\
\text { replace } \\
\text { with private } \\
\text { charge }\end{array}$ & $\begin{array}{l}\text { Refer to an } \\
\text { orthodontist }\end{array}$ & Other \\
\hline \multicolumn{3}{|c|}{ What would you do if the patient has fractured their removable retainer? } & 10.7 & 55.5 & 25 & 8.9 \\
\hline \multicolumn{3}{|l|}{ What would you do if the patient has lost their removable retainer? } & 12.5 & 57.1 & 21.5 & 8.9 \\
\hline \multicolumn{3}{|c|}{$\begin{array}{l}\text { What would you do if a bonded retainer has just detached from one or more teeth, but the } \\
\text { retainer is intact, the teeth remain well aligned and the retainer could be repaired? }\end{array}$} & 32.2 & 35.7 & 25 & 7.1 \\
\hline Question & $\begin{array}{l}\text { Replace } \\
\text { fixed } \\
\text { retainer with } \\
\text { NHS charge }\end{array}$ & $\begin{array}{l}\text { Replace } \\
\text { fixed } \\
\text { retainer } \\
\text { with private } \\
\text { charge }\end{array}$ & $\begin{array}{l}\text { Replace with } \\
\text { removable } \\
\text { NHS charge }\end{array}$ & $\begin{array}{l}\text { Replace with } \\
\text { removable } \\
\text { private } \\
\text { charge }\end{array}$ & $\begin{array}{l}\text { Refer to an } \\
\text { orthodontist }\end{array}$ & Other \\
\hline $\begin{array}{l}\text { What would you do if a bonded retainer has fractured and } \\
\text { needs replacing and the teeth remain well aligned? }\end{array}$ & 5.4 & 14.3 & 5.4 & 8.9 & 60.6 & 5.4 \\
\hline \multicolumn{3}{|l|}{ Question } & \multicolumn{2}{|c|}{ Yes } & \multicolumn{2}{|c|}{ No } \\
\hline \multicolumn{3}{|c|}{ Would you feel comfortable fitting a lingual bonded retainer to well-aligned teeth? } & \multicolumn{2}{|l|}{60} & \multicolumn{2}{|l|}{40} \\
\hline Question & \multicolumn{2}{|c|}{$\begin{array}{l}\text { Yes and I would not need } \\
\text { training to do this but would } \\
\text { require remuneration }\end{array}$} & \multicolumn{2}{|c|}{$\begin{array}{l}\text { Yes, if there was appropriate } \\
\text { training and remuneration }\end{array}$} & \multicolumn{2}{|c|}{$\begin{array}{l}\text { No, the orthodontist should } \\
\text { do this }\end{array}$} \\
\hline $\begin{array}{l}\text { Would you prefer to fit prescribed bonded retainers yourself at } \\
\text { the end of the course of orthodontic treatment provided by the } \\
\text { orthodontist? }\end{array}$ & \multicolumn{2}{|l|}{12} & \multicolumn{2}{|l|}{16} & \multicolumn{2}{|l|}{72} \\
\hline
\end{tabular}

- Q9: What would you do if a bonded retainer has fractured and needs replacing and the teeth remain well aligned? - Here, $60.6 \%$ said they would refer the patient to an orthodontist, with a fairly even distribution of the other respondents as to replacement with either a new fixed or removable retainer under private contract or the NHS

- Q10: Would you feel comfortable fitting a lingual bonded retainer to well-aligned teeth? - In answer to this question, $60 \%$ said they would be comfortable doing this and $40 \%$ said they wouldn't

- Q11: Would you prefer to fit prescribed bonded retainers yourself at the end of the course of orthodontic treatment provided by the orthodontist? - For this question, $72 \%$ said the orthodontist should do this. Much smaller percentages said they would either be happy to do this with remuneration $(12 \%)$ or following training and with remuneration (16\%).

\section{Discussion}

Orthodontic retention invariably entails a lifelong commitment for the patient, but most orthodontists are only likely to monitor retention for 12 to 24 months post-treatment, and therefore will often assume the patient's GDP will be happy to monitor retention and any ensuing dental change in the longer term. Good communication between the orthodontist and GDP is therefore essential so that, at the very least, both are fully aware when any shift in the responsibility towards retention is to take place and what might be required.

The importance of this communication has been highlighted in a previous audit of practitioners' knowledge of orthodontic retention. ${ }^{18}$ It was therefore disappointing to see that some five years later, as many as $44.6 \%$ of the respondents reported not receiving correspondence from the orthodontist requesting monitoring of the orthodontic retainers following discharge. It is accepted that effective two-way communication between two interdependent parties, namely primary and secondary care clinicians, is essential for the effective management of shared patients. ${ }^{19}$ This interdependence is present because the primary care providers refer suitable patients for treatment and secondary care providers often require the primary care provider to 
undertake routine maintenance and perhaps some of the treatment, which in the case of orthodontics would include supervision of retention. Previous work has often focused on the communication from primary to secondary care services, rather than in the other direction, highlighting some inadequacies ${ }^{20,21}$ and how this might be addressed using a referral pro forma. ${ }^{22}$ There are few studies investigating the standard of communication from secondary to primary care. However, it is understood that one of the pieces of information most valued by GDPs is the treatment plan sent by the secondary care provider. ${ }^{23}$ A survey of Swiss orthodontists found that $93 \%$ would welcome the development of retention guidelines to assist their own orthodontic practice and it would therefore seem sensible that similar guidelines, written as a pro forma, could usefully be provided by orthodontists to GDPs when they are asked to assume responsibility for the monitoring of long-term orthodontic retention. ${ }^{24}$

Despite this lack of communication, most GDPs do appear to monitor the orthodontic retention of their patients, although most patients either never $(25 \%)$ or hardly ever (46.4\%) bring their removable retainers to their routine dental appointments. It was also of some concern from a medico-legal perspective that this monitoring of retention is not always recorded in the patient record, and in the case of $7.8 \%$ of respondents, is never recorded.

In the case of fractured or lost removable retainers, most GDPs appear to be happy to replace them either free of charge or for a private fee, and less often refer them back to the orthodontist. The same is true for detached bonded retainers, whereas in the case of a bonded retainer with a fractured wire, the largest percentage would refer back to the orthodontist. In the case of a complete bonded retainer placement at the end of orthodontic treatment, although most GDPs were happy to fit one, they felt in most cases it should be fitted by the orthodontist. A small percentage felt they would require additional training and remuneration for carrying out this procedure, a point that has been made previously. ${ }^{17}$ Moreover, the desire for further training, concerning both placement of fixed retainers and management of orthodontic emergencies, has also been highlighted previously. ${ }^{18,25}$

Although research has shown that GDPs are able to detect features of relapse, such as the horizontal movement of incisors, more efficiently than both untreated and past orthodontic patients, ${ }^{5}$ the current questionnaire did not explore whether or not GDPs would be comfortable or able to monitor other aspects of the post-treatment occlusion, such as buccal segment relationships, overjet and overbite. For this, they may also require additional training and would certainly require access to the original pre- and post-treatment orthodontic records. The latter should now be possible with the increasing availability of electronic records, although this places an onus on provision of access, as well as possible storage of electronic records in the longer term.

Patients take much of the responsibility for retention, being expected to wear their retainers as instructed, maintain them and perhaps to some extent even monitor their own occlusion. Publicity campaigns to raise awareness of the need for prolonged retention have shown promise, at least in the short term. ${ }^{26}$ Any longer-term benefits may well depend on improved cooperation between orthodontists, GDPs and patients. Previous work investigating patient satisfaction with orthodontic treatment outcomes has shown that most patients feel responsible for maintaining the alignment of their own teeth and are satisfied with their outcome. Conversely, patients who were likely to be dissatisfied with the orthodontic outcome may be more likely to delegate responsibility for their retention. To this end, the expectation of the patient in taking responsibility for their own retention, along with continued monitoring by their GDP, should not only be part of informed consent at the start of treatment but should also be reinforced at the start of retention and again at discharge. The satisfaction with the type of retainer provided also has an impact on wear, with patients who had been prescribed clear retainers being very satisfied and therefore most likely to adhere to wear protocols. ${ }^{27}$ There will inevitably be some patients who will consider retention the sole responsibility of the orthodontist or GDP, perceiving retention as otherwise onerous and expensive, rather than an investment in maintaining their corrected occlusion. ${ }^{28}$ These patients are less likely to comply with the prescribed retention regimen and may require the most monitoring over the longer term, initially by the orthodontist and thereafter by the GDP.

A limitation of the current survey of GDPs is that it was a relatively small sample. This was attributed to the long delay in obtaining Ethical Committee approval at the time of the COVID-19 pandemic, compounded by the need for completion of the survey just as dental practices were resuming patient treatment following lockdown. Nevertheless, the results were informative and the trends generally clear. Moreover, the findings do appear to mirror those from previous, much larger national and international surveys, indicating that improved communication is required between orthodontists and GDPs in order to provide cohesive orthodontic care. ${ }^{18,24}$

\section{Conclusions}

There are usually three parties involved in the management of long-term retention, namely the orthodontist, the patient and the GDP. Typically, the patient and the GDP bear the most significant long-term commitment, something which is usually taken as read by the orthodontist. However, communication from the orthodontist to the GDP, including any guidance on how to manage retention, is often lacking. Despite this, many GDPs do appear happy to repair or replace retainers as required. However, it is clear that communication needs to improve. Just as many orthodontists are now keen for orthodontic referrals to be made on a pro forma to ensure appropriate information is provided to them to aid diagnosis, perhaps consideration should be given to routine adoption of a similar pro forma following orthodontic treatment to guide GDPs on bespoke monitoring of retention. More research on GDP opinions concerning this and other aspects of the management of orthodontic retention would be worthwhile.

\section{Conflict of interest}

The authors declare no conflict of interest.

\section{References}

1. Little R M. Stability and relapse of dental arch alignment. Br J Orthod 1990; 17: 235-241.

2. Årtun J, Krogstad O, Little R M. Stability of mandibular incisors following excessive proclination: a study in adults with surgically treated mandibular prognathism. Angle Orthod 1990; 60: 99-106.

3. Little R M, Wallen T R, Reidel R A. Stability and relapse of mandibular anterior alignment - first premolar extraction cases treated by traditional edgewise orthodontics. Am J Orthod 1981; 80: 349-365.

4. de Bernabé P G, Montiel-Company J M, ParedesGallardo V, Gandía-Franco J L, Bellot-Arcís C. Orthodontic treatment stability predictors: A retrospective longitudinal study. Angle Orthod 2017; 87: 223-229.

5. Alqahtani N, Preston B, Guan G. Perception of dental professionals and lay persons to altered mandibular incisors crowding. J World Fed Orthod 2012; DOl: 10.1016/j.ejwf.2012.06.002.

6. Ma W, Preston B, Asai Y, Guan H, Guan G. Perceptions of dental professionals and laypeople to altered maxillary incisor crowding. Am J Orthod Dentofacial Orthop 2014; 146: $579-586$. 
7. Chow L, Goonewardene M S, Cook R, Firth M J. Adult orthodontic retreatment: $A$ survey of patient profiles and original treatment failings. Am J Orthod Dentofacial Orthop 2020; 158: 371-382.

8. Vandevska-Radunovic V, Espeland L, Stenvik A. Retention: type, duration and need for common guidelines. A survey of Norwegian orthodontists. Orthodontics (Chic.) 2013; DOI: 10.11607/ortho.964.

9. Lai C S, Grossen J M, Renkema A M et al. Orthodontic retention procedures in Switzerland. Swiss Dent J 2014 124: 655-661.

10. Littlewood S, Millett D, Doubleday B, Bearn D, Worthington $H$. Retention procedures for stabilising tooth position after treatment with orthodontic braces. Cochrane Database Syst Rev 2016; DOI: 10.1002/14651858.CD002283.pub4.

11. Shaughnessy $T G$, Proffit W R, Samara S A. Inadvertent tooth movement with fixed lingual retainers. Am J Orthod Dentofacial Orthop 2016; 149: 277-286.

12. UK Government. The National Health Service (Dental Charges) Regulations 2005. 2005. Available online at https://www.legislation.gov.uk/ ukdsi/2005/0110736400 (accessed September 2020).

13. Hansa I, Semaan S, Vaid N. Clinical outcomes and patient perspectives of Dental Monitoring ${ }^{\circledast}$ GoLive with Invisalign ${ }^{\circledast}$ - a retrospective cohort study. Prog Orthod 2020; 21: 16
14. Hansa I, Semaan S J, Vaid N R, Ferguson D J. Remote monitoring and "Tele-orthodontics": concept, scope and applications. Semin Orthod 2018; 24: 470-481.

15. Al-Moghrabi D, Colonio Salazar F B, Johal A, Fleming PS. Factors influencing adherence to vacuum-formed retainer wear: A qualitative study. J Orthod 2019; 46: 212-219.

16. McCrory P V. British Orthodontic Society's initiative on orthodontic retention, $A$ GDP's perspective. Br Dent J 2018; 224: 481-486.

17. Littlewood S J. Responsibilities and retention. APOS Trends Orthod 2017; 7: 211-214

18. Kotecha S, Gale L, Khamashta-Ledezma J et al. A multicentre audit of GDPs knowledge of orthodontic retention. Br Dent J 2015; 218: 649-653.

19. Morris A, Burke F J T. Primary and secondary dental care: the nature of the interface. Br Dent J 2001; 191: 660-664

20. McAndrew R, Potts A J C, McAndrew M, Adam S. Opinions of dental consultants on the standard of referral letters in dentistry. Br Dent J 1997; 182: 22-25.

21. Izadi M, Gill D S, Naini F B. A study to assess the quality of information in referral letters to the orthodontic department at Kingston Hospital, Surrey. Prim Dent Care 2010; 17: 73-77.

22. Djemal S, Chia M, Ubaya-Narayange T. Quality improvement of referrals to a department of restorative dentistry following the use of a referral proforma by referring dental practitioners. Br Dent $J$ 2004; 197: 85-88.

23. Hammond M, Evans D R, Rock W P. A study of letters between general dental practitioners and consultant orthodontists. Br Dent J 1996; 180: 259-263.

24. Habegger M, Renkema A M, Bronkhorst E, Fudalej PS, Katsaros C. A survey of general dentists regarding orthodontic retention procedures. Eur Orthod 2017: 39: 69-75.

25. Popat H, Thomas K, Farnell D J. Management of orthodontic emergencies in primary care - self-reported confidence of general dental practitioners. Br Dent J 2016; 221: 21-24.

26. Valiji Bharmal R, Parker K, Caldwell S et al. A multicentre audit to assess the effectiveness of the British Orthodontic Society 'Hold that Smile' retainer videos. J Orthod 2020; 47: 72-77.

27. Mollov N D, Lindauer S J, Best A M, Shroff B, Tufekci E. Patient attitudes toward retention and perceptions of treatment success. Angle Orthod 2010; 80: 468-473.

28. Kearney M K, Pandis N, Fleming P S. Mixed-methods assessment of perceptions of mandibular anterior malalignment and need for orthodontic retreatment. Am J Orthod Dentofacial Orthop 2016; 150: 592-600.

\section{Appendix 1 The online questionnaire About yourself:}

1. I consent to participate in this study - yes/no

2. Are you a general dental practitioner mainly working in general dental practice? -yes/no

3. Do you deliver/hold an NHS general dental contact? - yes/no

4. Do you deliver/hold an NHS orthodontic contract? - yes/no

For your patients who have recently completed a course of orthodontic treatment and have been discharged by an orthodontist (specialist practice or hospital):

5. Do you receive correspondence from the orthodontist requesting that you now monitor the orthodontic retainers? - always; most of the time; sometimes; hardly ever; never

6. Does the correspondence give any specific information/guidance such as 'please monitor retainers annually' or 'please refer back if there are any problems'? - always; most of the time; sometimes; hardly ever; never

7. If the correspondence does give any specific information/guidance, please specify

\section{Regarding the monitoring of orthodontic retainers in general dental practice:}

8. Do you routinely enquire about/inspect the retainers of your patients at their routine general dental check-ups? - always; most of the time; sometimes; hardly ever; never

9. If you do enquire/inspect the retainers at their routine check-ups, do you record your findings in their clinical record? - always, most of the time; sometimes; hardly ever; never

10. Do your patients tend to bring their removable retainers to you to be reviewed at their routine general dental check-ups? - always; most of the time; sometimes; hardly ever; never

\section{When a patient presents at your general dental practice with a problem with their retainers:}

11. What would you do if the patient has fractured their removable retainer? - repair/replace with NHS charge; repair/replace with private charge; refer to an orthodontist; other

12. If you selected 'other', please specify

13. What would you do if the patient has lost their removable retainer? - replace with NHS charge; replace with private charge; refer to an orthodontist; other

14. If you selected 'other', please specify

15. What would you do if a bonded retainer has just detached from one or more teeth, but the retainer is intact, the teeth remain well aligned and the retainer could be repaired? - replace with NHS charge; replace with private charge; refer to an orthodontist; other

16. If you selected 'other', please specify

17. What would you do if a bonded retainer has fractured and needs replacing and the teeth remain well aligned? - replace with NHS charge; replace with private charge; remove residual bonded retainer and provide removable retainer with NHS charge; remove residual bonded retainer and provide removable retainer with private charge; refer to an orthodontist; other

18. If you selected 'other', please specify

19. Would you feel comfortable fitting a lingual bonded retainer to well-aligned teeth? -yes/no

20. Would you prefer to fit prescribed bonded retainers yourself at the end of the course of orthodontic treatment provided by the orthodontist? - yes and I would not need training to do this but would require remuneration; yes, if there was appropriate training and remuneration; no, the orthodontist should do this 